\title{
A Simplified Model of the Causation of Technological Unemployment
}

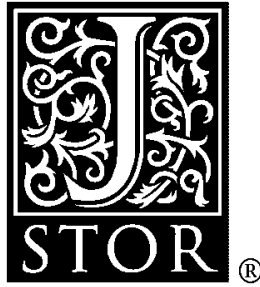

\author{
J. Tinbergen; P. de Wolff
}

Econometrica, Vol. 7, No. 3. (Jul., 1939), pp. 193-207.

Stable URL:

http://links.jstor.org/sici?sici=0012-9682\%28193907\%297\%3A3\%3C193\%3AASMOTC\%3E2.0.CO\%3B2-O

Econometrica is currently published by The Econometric Society.

Your use of the JSTOR archive indicates your acceptance of JSTOR's Terms and Conditions of Use, available at

http://www.jstor.org/about/terms.html. JSTOR's Terms and Conditions of Use provides, in part, that unless you have obtained prior permission, you may not download an entire issue of a journal or multiple copies of articles, and you may use content in the JSTOR archive only for your personal, non-commercial use.

Please contact the publisher regarding any further use of this work. Publisher contact information may be obtained at http://www.jstor.org/journals/econosoc.html.

Each copy of any part of a JSTOR transmission must contain the same copyright notice that appears on the screen or printed page of such transmission.

JSTOR is an independent not-for-profit organization dedicated to and preserving a digital archive of scholarly journals. For more information regarding JSTOR, please contact support@jstor.org. 


\title{
E C O N O M E T R I C A Volume 7 JuLr, $1939 \quad$ Number 3
}

\section{A SIMPLIFIED MODEL OF THE CAUSATION OF TECHNOLOGICAL UNEMPLOYMENT}

\author{
By J. Tinbergen and P. De WolfF
}

\section{INTRODUCTORY}

The purpose of the present paper is to find the influence on employment of some of the outstanding "data" (extra-economic determining factors). For this purpose, a simplified model has been constructed in which these data and the chief economic variables find their places. Since it is not intended to picture cyclic variations and causations, the model may be called a "long-run model." It excludes some of the most typical cyclical phenomena such as stock-exchange speculation and the existence of small lags of all kinds which are of importance to the explanation of cycles but do not seem to be so for long-run developments.

Since the investigators were interested chiefly in studying the consequences of technological development for employment and the consequences of some of the best-known devices to improve employment, special attention was given to the corresponding sections of economic life.

The calculations have been made for the United States prewar structure (using figures for 1910) and for the postwar pre-Roosevelt structure (using averages for 1919-1932).

\section{VARIABLES AND DATA INCLUDED IN THE ANALYSIS}

Variables: $a=$ total employment,

$b=$ employment in investment-goods industries,

$c=$ employment in consumers'-goods industries,

$u=$ volume of production of consumers' goods,

$\bar{u}=$ "normal" volume of production of consumers' goods, 1

$v=$ volume of production of investment goods,

$v_{-T}=$ ditto, $T$ units of time before,

$v_{e}=$ volume of production of investment goods for expansion of plant,

1 For explanation, ef. Section III. 
$p=$ consumers'-goods price level,

$q=$ investment-goods price level,

$\bar{n}=$ "normal" nonlabor remuneration contained in $p$,

$n^{\prime}=$ nonlabor remuneration contained in $q$,

$L=$ labor income (total wages),

$E=$ nonlabor income,

$E^{\prime}=$ nonlabor consumption outlay,

$E^{\prime \prime}=$ nonlabor savings.

Data: $\quad \bar{g}=$ "normal" labor quota in unit of consumers' goods, ${ }^{1}$

$\gamma=$ increase in labor contribution in such unit for increase in production by one unit,

$g^{\prime}=$ labor quota in unit of investment goods,

$h=$ deflated depreciation allowance per unit of product,

$T=$ lifetime of investment goods,

$l=$ wage rate,

$\mu=$ "transition period,"

$\Delta M=$ credit creation per time unit,

$\bar{E}=$ "normal" income of nonworkers,

$\bar{E}^{\prime}=$ "normal" expenditure of nonworkers on consumption,

$\epsilon=$ nonworkers' marginal propensity to consume,

$t=$ time.

Some of the terms have to be further explained and so has the choice of the data. This may best be done by discussing, one by one, the relations constituting our "model."

III. THE RELATIONS ASSUMED IN THE MODEL

(1) Starting with total employment $a$, this may be split up into two parts $b$ and $c$ :

$$
a=b+c .
$$

(2) Employment $b$ in investment-goods industries will be dependent on the volume $v$ of production of these goods by:

$$
b=g^{\prime} v,
$$

where $1 / g^{\prime}$ is labor productivity in this branch. The latter is assumed to be a given quantity, determined by technological development, but independent of $v$ and of the wage rate $l$. These simplifying hypotheses have not been made for consumers'-goods industries, but since investment-goods industries are far less important it was thought useful not to go into these details here.

(3) For consumers'-goods industries, the relation between employment $c$ and volume of production $u$ is taken as: 


$$
c=\left\{\bar{g}+\frac{1}{2} \gamma(u-\bar{u})\right\} u .
$$

This comes to assuming that the inverted labor productivity or the labor quota per unit of product is a linear function of the volume of production itself; $\bar{u}$ is a reference value of the latter, which may be called the "normal" production. For $u=\bar{u}$, the quantity of labor required per unit equals $\bar{g}$, which is given by technical development. It will be assumed also to depend on wage rates, but since wage rates are also considered as data-for reasons to be set out afterwards-this dependency may be considered later (Section 6, B). There is no serious restriction in the linearity of the function if we consider only small variations in volume of production. The chief reason why inverted productivity depends on the volume of production will be that for a larger production less efficient plants, or parts of plants, or methods, will be necessary.

(4) The volume of investment-goods production $v$ may be split up into two parts, production for replacement and production for expansion of plant; the former is assumed to be equal to total production of investment goods, $T$ time units before, where $T$ is the lifetime of investment goods (including, apart from machines, also buildings and even houses).

We therefore get:

$$
v=v_{-T}+v_{e} .
$$

(5) The volume of production of consumers' goods $u$ will be determined, in the first instance, by incomes spent and price level. It is assumed that wages are spent wholly; this leads to:

$$
u p=L+E^{\prime} .
$$

(6) In a sense this is only a tautology, which has to be completed by an equation telling how consumption outlay $E^{\prime}$ by nonworkers depends on their incomes; this is assumed to satisfy the relation:

$$
E^{\prime}=\bar{E}^{\prime}+\epsilon(E-\bar{E}) .
$$

The relation is linear, which again is no serious restriction if small variations are considered. The coefficients $\bar{E}, \bar{E}^{\prime}$, and $\epsilon$ may be called "normal" income, "normal" expenditure, and marginal propensity to consume, respectively.

(7) The two income categories included in the foregoing analysis both depend on economic activity. Total wages $L$ are simply the product of employment $a$ and wage rate $l$ :

$$
L=a l .
$$

Nonlabor income will be discussed later. 
(8) The formation of prices may reasonably be treated first. Since long-run relations are considered, prices may be said to equal marginal cost. Marginal cost for consumers' goods will consist of :

(i) Marginal remuneration of nonworkers: $\bar{n}$;

(ii) Marginal labor cost. Since total labor cost equals $c l=\{\bar{g}+$ $\left.\frac{1}{2} \gamma(u-\bar{u})\right\} u l$, marginal labor cost will be found by differentiation with respect to $u$ and be equal to:

$$
\left\{\bar{g}+\gamma\left(u-\frac{1}{2} \bar{u}\right)\right\} l ;
$$

(iii) Depreciation allowances. For simplicity and since they are only a small proportion of total costs these are assumed to be independent of the volume of production, but proportional only to prices of investment goods; they will be indicated by $h q$.

Adding up, we get:

$$
p=\bar{n}+\left\{\bar{g}+\gamma\left(u-\frac{1}{2} \bar{u}\right)\right\} l+h q .
$$

(9) Since investment goods play a less important role than consumers' goods, their prices $q$ are not considered in so much detail. Depreciation allowances will for the prewar case be neglected, and, as before, $g^{\prime}$ is considered to be independent of $v$.

$$
q=g^{\prime} l+n^{\prime} .
$$

For the postwar case, calculations including depreciation allowances have also been made, using the formula:

$$
q=g^{\prime} l+n^{\prime}+q h .
$$

For simplicity, $h$ has been taken equal for both groups of industries. The resulting errors are small.

(10) We are now able to calculate nonlabor income, by subtracting, from the total value of production $p u+q v$, depreciation allowances $h u q$ (for postwar calculations $h u q+h v q$ ), and wages

$$
\begin{gathered}
a l=\left[\left\{\bar{g}+\frac{1}{2} \gamma(u-\bar{u})\right\} u+g^{\prime} v\right] l \text {; the result being: } \\
E=u \bar{n}+\frac{1}{2} u^{2} l+v n^{\prime} .
\end{gathered}
$$

(11) One self-evident relation may be added here:

$$
E^{\prime}+E^{\prime \prime}=E \text {. }
$$

(12) Turning to the sphere of capital formation we have to ask: What funds are available and how are they spent? The funds are:

(i) the stream of savings, $E^{\prime \prime}$ per time unit;

(ii) newly created credits, $M$ (provisional notation) per time unit;

(iii) a money stream coming into existence since the accumulated 
depreciation allowances are not fully used for replacement-replacement being equal to investment-goods production $T$ time units ago and depreciation allowances being based on plant existing at this moment. These funds yield a stream of $\left(u h+v h-v_{-T}\right) q$ [in the prewar case $\left.\left(u h-v_{-T}\right) q\right]$.

This total is spent for two purposes:

(i) the purchase of durable capital goods, as far as they represent new investment; their value is $v_{e} q$; and

(ii) wage and other income payments connected with an expansion of business. These sums have to be paid for a transition period only; after this period the receipts from increased production will enable the entrepreneurs to pay increased incomes. Indicating the rate of increase in total wages by $\dot{L}$, that in other incomes by $\dot{E}$, and the length of the transition period by $\mu$, the necessary amount-sometimes referred to as increase in circulating capital-will be $\mu(\dot{L}+\dot{E})$. The period $\mu$ may be estimated roughly by putting it equal to the circulation period of income, i.e., total money in circulation $M$, divided by income $L+E$.

The foregoing leads to the equation:

$$
E^{\prime \prime}+\dot{M}+\left(u h+v h-v_{-T}\right) q=v_{e} q+\mu(\dot{L}+\dot{E}),
$$

which, since $v=v_{-T}+v_{e}$, may be written:

$$
E^{\prime \prime}+\dot{M}+(u h+v h-v) q=\mu(\dot{L}+\dot{E}) .
$$

In some calculations this will be simplified into:

$$
E^{\prime \prime}+\dot{M}+(u h-v) q=\mu(\dot{L}+\dot{E}) .
$$

Of course, this equation does not tell anything about the motives of investment activity. This question will be considered later (Section IV).

(13) There remains one further equation to be discussed, viz., the one between accumulated investment (in the physical sense) and the normal capacity to produce. Since $v$ represents the volume of production of investment goods per unit of time, and $T$ the lifetime of these goods, there will, at any moment $t$, be in existence a quantity of $\int_{t-T}^{t} v_{\tau} d \tau$ of them. Per unit of time, $1 / T$ of this quantity will normally be "consumed" in the production process. This consumption represents the "contribution," $h(\bar{u}+\bar{v})$, to the normal production $\bar{u}$ and $\bar{v}$ of consumers' and investment goods, respectively, $h$ being the factor introduced as "deflated depreciation allowance."

Thus we get:

$$
h(\bar{u}+\bar{v}) T=\int_{t-T}^{t} v_{\tau} d \tau
$$


Since we will find $T$ to be equal to about $2 \frac{1}{2}$ units of 10 years, we may replace the integral by:

$$
\int_{t-1}^{t} v_{\tau} d \tau+\int_{t-2}^{t-1} v_{\tau} d \tau+\int_{t-2 \frac{1}{2}}^{t-2} v_{\tau} d \tau
$$

and since $v_{t}$ will, in what follows, indicate the volume of production of investment goods in a finite period of which $t$ is the centre, this sum equals, approximately:

$$
\frac{1}{2}\left(v_{t}+v_{t-1}\right)+\frac{1}{2}\left(v_{t-1}+v_{t-2}\right)+\frac{1}{4}\left(v_{t-2}+v_{t-3}\right) .
$$

Our equation becomes, therefore:

$$
h(\bar{u}+\bar{v}) T=\frac{1}{2} v_{t}+v_{t-1}+\frac{3}{4} v_{t-2}+\frac{1}{4} v_{t-3} .
$$

Since, in our prewar calculation and in one of the postwar calculations, we neglect depreciation allowances in investment-goods industries, in these cases equation (13) will be replaced by:

$$
h \bar{u} T=\frac{1}{2} v_{t}+v_{t-1}+\frac{3}{4} v_{t-2}+\frac{1}{4} v_{t-3} .
$$

\section{DATA, UNKNOWNS, AND CONSTANTS}

The equations (1) to (13) will be used for the description of long-term movements of employment and other economic phenomena. In this description some of the phenomena introduced will be considered as data, others as "phenomena to be explained." Our distinction will not quite coincide with that of usual theory. A few words may therefore be added to defend our choice. We shall consider as data:

(i) The technical coefficients $\bar{g}, g^{\prime}, h, T$, and $\gamma$, determining, to some extent, the production function of our model society;

(ii) The psychological coefficients $\bar{E}^{\prime}$ and $\epsilon$, determining the behavior of consumers (nonworkers);

(iii) The institutional coefficient $\mu$, intimately connected with the velocity of circulation of money;

(iv) The wage rate $l$ and the rate of increase in circulation $\dot{M}$. These will, in general, be considered as economic phenomena, to be explained by theory. Both of them are, however, in present circumstances, highly subject to policy. Our procedure will be to consider them as independent variables and to find out how the choice of their magnitude influences employment and other economic phenomena. If then a certain change in $l$, say $\Delta^{\prime} l$, is found to be the most favorable change for a given purpose, it may quite well be that "natural developments," i.e., normal economic forces, lead already to a change $\Delta^{\prime \prime} l$; the task of policy then being to complement this $\Delta^{\prime \prime} l$ until the total value $\Delta^{\prime} l$ is reached. For the solution of such problems it is not necessary to know 
the "natural development" $\Delta^{\prime \prime} l$. Similar remarks may be made with respect to $\dot{M}$. The "regular" motives to investment are no longer of importance to its determination as soon as complementary government investments (public works and deficit financing) are included as a possibility.

(v) The remunerations per unit of product $\bar{n}$ of the marginal nonworker in consumers'-goods industries and $n^{\prime}$ of nonworkers in investment-goods industries. These are considered as constants-and therefore as given-since:

(a) In most literature about technological unemployment not much attention is given to their movements;

(b) Many elements in them will in fact be very sticky, such as interest, rent, and "the adequate income" of an independent entrepreneur. Interest and rent are often fixed for very long times and "the adequate income" is something largely determined by tradition and past experience.

In order to be quite sure that the hypothesis of constant $\bar{n}$ and $n^{\prime}$ is not a dangerous one, additional calculations have been made where, instead of $\bar{n}$, total nonworkers, income was considered constantmeaning that the remuneration per unit of product varies inversely with production volume $u$-and the deviations with our case appeared to be small.

Not all data have been supposed to be constant. Apart from $\bar{n}$ and $n^{\prime}$, just mentioned, this has been assumed to be so for $\gamma, T, \bar{E}^{\prime}, \epsilon$, and $\mu$. On the other hand, $l, \bar{g}, g^{\prime}, h$, and $\dot{M}$ have been considered as (independently) variable. And the problem solved is that of the change in employment, prices, incomes, and production occurring as a consequence of given changes in the independent variables.

In order to solve this problem it is convenient to combine some of the equations and to differentiate them with respect to time. This latter device is not carried out for equation (12), which already contains differential coefficients. In order to simplify concrete calculations, finite (but small) rates of increase are substituted for differential coefficients. These do not relate, strictly speaking, to time period $t$, but to the moment between $t$ and $t+1$. For uniformity, equation (12) is also brought into the form relating to that moment, which comes to adding to any term like $E^{\prime \prime}$ a term $\frac{1}{2} \Delta E^{\prime \prime}$. All these operations combined lead us to the following system of equations:

$$
\begin{gathered}
\Delta a=\left\{\bar{g}+\frac{1}{2} \gamma(u-\bar{u})\right\} \Delta u+u\left\{\Delta \bar{g}+\frac{1}{2} \gamma(\Delta u-\Delta \bar{u})\right\}+v \Delta g^{\prime}+g^{\prime} \Delta v, \\
\Delta v=\Delta v_{-T}+\Delta v_{e},
\end{gathered}
$$

$$
\Delta p=\left\{\bar{g}+\gamma\left(u-\frac{1}{2} \bar{u}\right)\right\} \Delta l+l\left\{\Delta \bar{g}+\gamma\left(\Delta u-\frac{1}{2} \Delta \bar{u}\right)\right\}+h \Delta q+q \Delta h
$$




$$
+\frac{1}{2} q(h \Delta u+h \Delta v-\Delta v)+\frac{1}{2} q u \Delta h+\frac{1}{2} q v \Delta h+\Delta M=\mu(\Delta E+a \Delta l+l \Delta a),
$$

$$
\begin{aligned}
\Delta E & =\bar{n} \Delta u+n^{\prime} \Delta v+\gamma l u \Delta u+\frac{1}{2} \gamma u^{2} \Delta l, \\
\frac{\bar{u}+\bar{v}}{\bar{v}} \Delta \bar{u}= & \frac{\frac{1}{2} \Delta v_{-3}+1 \frac{1}{2} \Delta v_{-2}+2 \Delta v_{-1}+\Delta v}{2 h T} \\
& -\frac{\frac{1}{2} v_{-3}+1 \frac{1}{2} v_{-2}+2 v_{-1}+v}{2 h^{2} T} \Delta h .
\end{aligned}
$$

In the establishment of the last of these equations a further hypothesis has been made, in order to avoid consideration of some unimportant details: it has been assumed that $\Delta \bar{u}$ and $\Delta \bar{v}$ show the same proportion as $\bar{u}$ and $\bar{v}$.

As has already been stated in the discussion of the separate equations, several cases have been considered. The above system of equations relates to one (the most complete) postwar calculation. A simpler calculation has been made with postwar and with prewar figures. In these latter calculations depreciation allowances for investment-goods industries have been neglected; this leads to the equations indicated with a prime and gives the following equations instead of (17), (19), and (21):

$$
\begin{gathered}
\Delta q=g^{\prime} \Delta l+l \Delta g^{\prime} \\
E^{\prime \prime}+\frac{1}{2}(1-\epsilon) \Delta E+(h u-v) q+\frac{1}{2}(h u-v) \Delta q+\frac{1}{2} q(h \Delta u-\Delta v) \\
+\frac{1}{2} q u \Delta h+\Delta M=\mu(\Delta E+a \Delta l+l \Delta a),
\end{gathered}
$$

$\left(21^{\prime}\right) \Delta \bar{u}=\frac{\frac{1}{2} \Delta v_{-3}+1 \frac{1}{2} \Delta v_{-2}+2 \Delta v_{-1}+\Delta v}{2 h T}-\frac{1}{2 h^{2} T} \Delta h\left(\frac{1}{2} v_{-3}+1 \frac{1}{2} v_{-2}+2 v_{-1}+v\right)$.

The unknowns of this system are $\Delta a, \Delta u, \Delta v, \Delta v_{e}, \Delta E, \Delta p, \Delta q$, and $\Delta \bar{u}$; the independent variables: $\Delta l, \Delta \bar{g}, \Delta g^{\prime}, \Delta h, \Delta M$. The coefficients in these equations are all magnitudes relating to the actual situation and to some extent represent the economic structure as far as it seems to be important for long-run changes.

\section{STATISTICAL INFORMATION}

We have attempted to measure approximately the values of the coefficients in equations (14) to $(21)$ and $\left(17^{\prime}\right),\left(19^{\prime}\right)$, and $\left(21^{\prime}\right)$. This 
required a considerable amount of statistical work, the details of which would take far too much space to be given here. Of course great accuracy cannot be claimed for the results obtained. Some further trials have shown, however, that the character of most of the results obtained does not change very much, if the statistical values taken are replaced by different values based on uncertainty margins estimated. All this must, however, be preserved for a subsequent monograph.

Before mentioning the figures used something must be said on the system of units used. For both time points considered the following principles for the choice of units have been applied:

(i) All prices have been taken equal to one;

(ii) All money amounts have been measured in total wages bill as unit.

TABLE 1

Summary of Statistical Information Used

\begin{tabular}{|c|c|c|c|}
\hline $\begin{array}{c}\text { Sym- } \\
\text { bol }\end{array}$ & Description & $\begin{array}{l}\text { Value } \\
1910\end{array}$ & $\begin{array}{c}\text { Average } \\
\text { value } \\
1919- \\
1932 \ddagger\end{array}$ \\
\hline$g$ & $\begin{array}{l}\text { Mean labor quota in consumers'-goods industries } \\
\text { for normal production }\end{array}$ & 0.40 & 0.54 \\
\hline$\gamma$ & $\begin{array}{l}\text { Increase of marginal labor quota in consumers'- } \\
\text { goods industries per unit of increase in output }\end{array}$ & 0.11 & 0.13 \\
\hline$u$ & Volume of production of consumers' goods & 1.83 & 1.51 \\
\hline$u$ & $\begin{array}{l}\text { "Normal" volume of production of consumers' } \\
\text { goods }\end{array}$ & 1.83 & 1.51 \\
\hline$g^{\prime}$ & Labor quota in investment-goods industries & 0.75 & 0.70 \\
\hline$v$ & Volume of production of investment goods & 0.34 & 0.37 \\
\hline$h$ & Deflated* depreciation allowance per unit of output & 0.07 & 0.10 \\
\hline$\epsilon$ & Marginal propensity to consume for nonworkers & 0.70 & 0.70 \\
\hline$E^{\prime \prime}$ & Amount of total savings & 0.22 & 0.21 \\
\hline$\mu$ & Transition period $\dagger$ (unit: 10 years) & 0.05 & 0.07 \\
\hline$\dddot{n}$ & $\begin{array}{l}\text { "Normal" remuneration of nonworkers per unit of } \\
\text { output of consumers' goods } \dagger\end{array}$ & 0.43 & 0.26 \\
\hline$n^{\prime}$ & $\begin{array}{l}\text { Remuneration of nonworkers per unit of output of } \\
\text { investment goods }\end{array}$ & 0.25 & 0.20 \\
\hline$T$ & Lifetime of investment goods (unit: 10 years) & 2.5 & 2.5 \\
\hline$v_{-3}$ & $\begin{array}{l}\text { Volume of production of investment goods in time } \\
\text { period }-3\end{array}$ & 0.07 & 0.10 \\
\hline$v_{-2}$ & $\begin{array}{l}\text { Volume of production of investment goods in time } \\
\text { period }-2\end{array}$ & 0.12 & 0.24 \\
\hline$v_{-1}$ & $\begin{array}{l}\text { Volume of production of investment goods in time } \\
\text { period }-1\end{array}$ & 0.18 & 0.36 \\
\hline
\end{tabular}

* I.e., depreciation allowance if prices of consumers' goods and of investment goods are taken equal to one.

$\dagger$ For explanation of term, see text.

$\ddagger$ The principle underlying the choice of units invalidates, in some respects, the comparability of the last column with the last but one. 
From (i) it follows that - at the moment considered-each quantity figure $(a, u, v$, etc.) is equal to the corresponding value figure $(L, u p$, $v q$, etc.). From (ii) it follows that-at that same moment- $a=1$, since $L=1$ and $l=1$. Of course this is not necessarily the case for any later moment, since all variables considered may change.

Given this system of units, certain comparisons between the 1910 and the 1919-1932 figures are not possible. The values $u=1.83$ for 1910 and $u=1.51$ for 1919-1932 do not mean, e.g., that the volume of production fell. They mean that the value of production of consumers' goods fell in proportion to total wages.

The figures used are given in Table 1 . The reader will easily find all he wants for substituting in the equations (14)-(21). An exception must be made for the values $\Delta v_{-3}, \Delta v_{-2}$, and $\Delta v_{-1}$. These are, however, only contributing to the nonvariable terms in the equations which do not interest us for our problem and which have, therefore, not even been calculated.

One general remark may be added. The aim of statistical measurement has not been to test the equations (1) to (12). On the contrary, these have been considered as generally accepted and a number of the structural coefficients have been calculated with their help. Only equation (13) will be found not to be satisfied; the values found for the right-hand member and the left-hand member are rather divergent. There may be good reasons for this. Anyhow, the consequences of this discrepancy for our results have been calculated and were found to be unimportant.

\section{RESULTS OF CALCULATIONS}

Putting in the figures and solving for the unknown yields the results given in Table 2 .

The first line of Table 2 means:

Case 1: $\Delta a=-0.55 \Delta l+0.97 \Delta \bar{g}+0.11 \Delta g^{\prime}+2.18 \Delta h+9.42 \Delta M+$ constant, and so on.

The application of these results to concrete problems requires some caution in that often changes in one of the independent variables may entail changes in others. This must be considered carefully for each case treated.

\section{A. Technical Progress and Employment.}

Technical progress may be taken to mean any change in technical coefficients yielding lower costs per unit of product than before. Disregarding for a moment $g^{\prime}$, the reduction may be the result of :

(i) a reduction in $\bar{g}$, with an accompanying (but smaller) increase in $h(l$ and $q$ are supposed to be one); commonly known as mechanisation; 
(ii) a reduction $\bar{g}$ without a change in $h$, mostly known as rationalisation; and

(iii) a reduction in $h$ with or without a (smaller) increase in $\bar{g}$. Such cases will frequently represent what Schumpeter called "new combinations."

TABLE 2

Results of Calculations

Coefficients obtained in solution for left-hand variable.

\begin{tabular}{|c|c|c|c|c|c|c|}
\hline Case & & $\Delta l$ & $\Delta \vec{g}$ & $\Delta g^{\prime}$ & $\Delta h$ & $\Delta M$ \\
\hline $\begin{array}{l}1 \\
2 \\
3\end{array}$ & $\Delta a=$ & $\begin{array}{l}-0.55 \\
-0.92 \\
-1.03\end{array}$ & $\begin{array}{r}+0.97 \\
+0.59 \\
+0.59\end{array}$ & $\begin{array}{r}+0.11 \\
+0.29 \\
+0.13\end{array}$ & $\begin{array}{l}+2.18 \\
+\quad 1.08 \\
+\quad 1.49\end{array}$ & $\begin{array}{r}+9.42 \\
+8.72 \\
+8.72\end{array}$ \\
\hline $\begin{array}{l}1 \\
2 \\
3\end{array}$ & $\Delta u=$ & $\begin{array}{l}-0.79 \\
-1.13 \\
-1.29\end{array}$ & $\begin{array}{l}-1.37 \\
-1.17 \\
-1.17\end{array}$ & $\begin{array}{l}-0.20 \\
+0.078 \\
-0.13\end{array}$ & $\begin{array}{l}-3.94 \\
-2.87 \\
-4.46\end{array}$ & $\begin{array}{r}+14.96 \\
+11.04 \\
+11.04\end{array}$ \\
\hline $\begin{array}{l}1 \\
2 \\
3\end{array}$ & $\Delta v=$ & $\begin{array}{l}-0.35 \\
-0.36 \\
-0.39\end{array}$ & $\begin{array}{l}-0.38 \\
-0.33 \\
-0.33\end{array}$ & $\begin{array}{l}-0.28 \\
-0.24 \\
-0.28\end{array}$ & $\begin{array}{l}+\quad 0.89 \\
+\quad 0.99 \\
+\quad 2.54\end{array}$ & $\begin{array}{r}+4.20 \\
+\quad 3.10 \\
+\quad 3.10\end{array}$ \\
\hline $\begin{array}{l}1 \\
2 \\
3\end{array}$ & $\Delta E=$ & $\begin{array}{l}-0.40 \\
-0.44 \\
-0.52\end{array}$ & $\begin{array}{l}-0.96 \\
-0.60 \\
-0.60\end{array}$ & $\begin{array}{l}-0.20 \\
-0.012 \\
-0.12\end{array}$ & $\begin{array}{l}-2.26 \\
-1.12 \\
-1.55\end{array}$ & $\begin{array}{r}+10.48 \\
+\quad 5.70 \\
+\quad 5.70\end{array}$ \\
\hline $\begin{array}{l}1 \\
2 \\
3\end{array}$ & $\Delta p=$ & $\begin{array}{r}+0.52 \\
+0.60 \\
+0.59\end{array}$ & $\begin{array}{r}+0.91 \\
+0.88 \\
+0.88\end{array}$ & $\begin{array}{l}+0.093 \\
+0.14 \\
+0.12\end{array}$ & $\begin{array}{l}+2.48 \\
+2.10 \\
+\quad 3.23\end{array}$ & $\begin{array}{l}+0.98 \\
+\quad 1.11 \\
+\quad 1.11\end{array}$ \\
\hline $\begin{array}{l}1 \\
2 \\
3\end{array}$ & $\Delta q=$ & $\begin{array}{r}+0.75 \\
+0.70 \\
+0.78\end{array}$ & - & $\begin{array}{r}+1.00 \\
+1.00 \\
+1.11\end{array}$ & $\overline{-} \overline{1.11}$ & - \\
\hline $\begin{array}{l}1 \\
2 \\
3\end{array}$ & $\Delta v_{e}=$ & $\begin{array}{l}-0.35 \\
-0.36 \\
-0.39\end{array}$ & $\begin{array}{l}-0.38 \\
-0.33 \\
-0.33\end{array}$ & $\begin{array}{l}-0.28 \\
-0.24 \\
-0.28\end{array}$ & $\begin{array}{r}+0.89 \\
+0.99 \\
+\quad 2.54\end{array}$ & $\begin{array}{l}+4.20 \\
+\quad 3.10 \\
+\quad 3.10\end{array}$ \\
\hline $\begin{array}{l}1 \\
2 \\
3\end{array}$ & $\Delta \bar{u}=$ & $\begin{array}{l}-1.00 \\
-0.58 \\
-0.62\end{array}$ & $\begin{array}{l}-1.11 \\
-0.53 \\
-0.53\end{array}$ & $\begin{array}{l}-0.82 \\
-0.38 \\
-0.45\end{array}$ & $\begin{array}{l}-34.82 \\
-22.60 \\
-26.23\end{array}$ & $\begin{array}{r}+12.14 \\
+\quad 5.01 \\
+\quad 5.01\end{array}$ \\
\hline
\end{tabular}

1. Prewar case [equations (14)-(21) with primes where they exist].

2. Comparable postwar case (same equations, but postwar figures).

3. Complete postwar case (equations without primes).

The remarkable result obtained by our calculations is that reductions in $\bar{g}$ (increases in labor productivity) are unfavorable to employment. This stands in contrast to what is known as the compensation theory. Let us go into some more detail here.

Since $a=g u+g^{\prime} v$, where $g$ is the amount of labor per unit of con- 
sumers'-goods output, the direct consequence of a change in $g$ may be taken to mean $\Delta a=u \Delta g$, the change in $a$ for constant $u$, which, under these circumstances, is equal to $u \Delta \bar{g}$ or $1.83 \Delta \bar{g}$ in the prewar case and $1.51 \Delta \bar{g}$ in the postwar case. The compensation theory (whatever form it be given) holds that this direct, unfavorable, influence is offset by indirect consequences, which evidently result in changes in production. A number of these indirect consequences are taken account of in our calculations, as, e.g., price change, influence of change in incomes, etc. Our results show that these repercussions are not able to compensate for more than about 50 per cent of the direct influence.

Our results do not include repercussions via the other independent variables. But they could be made to do so if we knew how much $l, M$, etc., change for a given change in $\bar{g}$. There is little reason to include changes in $l$. Most authors are interested in knowing whether there will be compensation without wage changes.

Changes in $h$ and in $M$ may, however, be included. But it is not easy to see what relation exists between a given change $\Delta \bar{g}$ in $\bar{g}$, and the changes in $h$ and $M$ that accompany them.

As to changes in $h$ only a certain limit can be indicated: it is in the nature of technical progress that $\Delta \bar{g}+\Delta h<0$, since the left-hand side represents the increase in cost of production per unit. This does not, however, in our case give very narrow limits as to the results of changes in $h$. If $\Delta h=-\Delta \bar{g}$ (one extreme) we find that full compensation would be obtained, since in $\Delta a$ the coefficient for $\Delta h>$ that for $\Delta \bar{g}$. If, on the other hand, $\Delta h=0$, which is certainly within the limit of possibilities, our previous conclusion still holds. From this it seems that the consequences of technical progress on employment are widely divergent for various types of technical changes. It may therefore be useful to know something on the actual changes in $\bar{g}$ and $h$. Our-admittedly very rough-estimates for the United States as a whole over the period 1850-1910 suggest that there is not a very close relation between $-\Delta \bar{g}$ and $\Delta h$, and, as far as such a relation exists, $-\Delta \bar{g}$ is about ten times as large as $\Delta h$. This would be somewhat reassuring, since it would mean that the influence of changes in $h$ on employment is not so large. ${ }^{2}$

There remains the question of the repercussion on $M$. It is equally difficult to see of what nature and extent this repercussion is. It could be argued that an increase in labor productivity stimulates new investment activity and therefore $\Delta M$. This connection is not, however,

2 Similar calculations were made for the Netherlands. The coefficient found for $\Delta \bar{g}$ was very near to that found for the U. S., but the coefficient found for $\Delta h$ was much smaller. The difficulty just dealt with did not exist therefore for that country. 
necessarily very intimate. It depends on the character of the technical change. An increase in labor productivity may, but need not, be accompanied by an increase in real investment. Therefore it seems better to hold separated the two phenomena and to state explicitly that our conclusions concerning partial compensation bear on the case where no additional investment occurs as a consequence of the change in $g$.

\section{B. Wages and Employment: the Elasticity of the Demand Sor Labor.}

Our formulae enable us to find, as a by-product, what influence on employment is exerted by a change in wage rates. By the choice of our units the coefficients for $\Delta l$ found in the equations for $\Delta a$ are equal to the elasticity of demand for labor. This elasticity would be somewhat more than one-half for 1910 and about unity for the postwar period. Some qualifications must, however, be kept in mind. First, that we are dealing with long-run elasticities and that our figures do not take account of such cyclic phenomena as hoarding in depression. Secondly, that they have been made under the hypotheses enumerated, of which the most important one is that no changes in the other independent variables occur as a consequence of the wage-rate change. This means in particular that labor productivity would not be affected by a change in wages. It seems more realistic, at least for the very long run (after a couple of years, e.g.), to assume that the technical constants $\bar{g}, g^{\prime}$, $h$ are functions of the wage rate. It is not easy to get accurate information on these functions which, by the way, must depend on the production function. A very rough estimate, based on a study by Professor Gustav Åkerman ${ }^{3}$ may be made in the following way. Professor Åkerman found that, out of 19 cases of rationalisation which he studied, $12 \frac{1}{2}$ were due to increases in real wages (cases which were described as only partly due to increases in real wages being counted for one-half), whereas out of these $12 \frac{1}{2}$ cases, $6 \frac{1}{2}$ would, in the case of a wage reduction, be undone again. There is, therefore, a clear indication of "hysteresis": a different reaction for $\Delta l>0$ and $\Delta l<0$. We may summarize the situation by saying that $0.5 \pm 0.2$ of the cases of rationalisation were due to wage changes, where the upper sign relates to wage rises and the lower to wage falls. Now $\Delta \bar{g}$ was, between 1921 and 1931, in our units, equal to -0.14 , whereas $\Delta(l-p)$, representing the change in real wage rate, amounted to +0.22 . If, since we have to do with a rise in wage rates, $7 / 10$ of the fall in $\bar{g}$ or -0.10 is to be attributed to the change +0.22 in $l-p$, then the relation between $\Delta \bar{g}$ and $\Delta(l-p)$ must be

3 "Om den industriella rationaliseringen och dess verkningar," Arbetslöshetsutredningens betänkande I, Bilagor, Band 2, Stockholm 1931. 


$$
\Delta \bar{g}=-\frac{0.10}{0.22} \Delta(l-p)+\Delta \bar{g}
$$

for wage rises, where $\overline{\bar{g}}$ is the part of $\bar{g}$ which is to be attributed to other factors than wages. For wage falls the coefficient has to be changed in the proportion 0.7 to 0.3 . We therefore get:

$$
\begin{aligned}
& \bar{g}=-0.45 \Delta(l-p)+\Delta \overline{\bar{g}} \text { for } \Delta(l-p)>0 \\
& \bar{g}=-0.19 \Delta(l-p)+\Delta \overline{\bar{g}} \text { for } \Delta(l-p)<0,
\end{aligned}
$$

or summarized: $\quad \Delta \bar{g}=-(0.32 \pm 0.13) \Delta(l-p)+\Delta \bar{g}$.

This may now be combined with our results for case $3: \Delta a=-1.03 \Delta l+$ $0.59 \Delta \bar{g}$, neglecting further terms, and $\Delta p=0.59 \Delta l+0.88 \Delta \bar{g}$, neglecting further terms.

It follows that

or

$$
\begin{aligned}
& \Delta \bar{g}=-(0.32 \pm 0.13)[\Delta l-0.59 \Delta l-0.88 \Delta \bar{g}]+\Delta \bar{g} \\
& \Delta \bar{g}=-(0.17 \pm 0.04) \Delta l+(1.4 \pm 0.2) \Delta \bar{g} .
\end{aligned}
$$

Finally,

$$
\Delta a=-1.03 \Delta l-(0.10 \pm 0.02) \Delta l+(0.83 \mp 0.12) \Delta \vec{g} .
$$

The elasticity of demand for labor would, according to this rough evaluation, not be changed considerably by the reaction on $\bar{g}$ which is exerted by $l$. And in this correction the influence on $h$, which will generally be of the opposite sign, has even been neglected.

\section{Hours and Employment: the Influence of a 40-Hour Week on Employment.}

We are also able to find the influence of a change in working hours from, say, 48 to 40 . Taking a week as the unit of labor, this means that $\bar{g}$ and $g^{\prime}$ will rise in the proportion 5:6; thus $\Delta \bar{g}=0.11$ and $\Delta g^{\prime}=0.14$. The effect on $h$ is not certain; if depreciation were proportional to production, no change in $h$ would be involved; if it were proportional to time, a maximum change in $h$ of $1 / 5$ or 0.02 would be the effect of the change in hours; therefore $\Delta h=0.01 \pm 0.01$. As to wages, two different cases may be considered; first, no change in weekly wages which means that $\Delta l=0$; secondly, a proportionate reduction in weekly wages, meaning that $\Delta l=-0.17$. Using formula (3) we find:

\begin{tabular}{c||c|c}
$\Delta a$, for: & $\Delta h=0$ & $\Delta h=0.02$ \\
\hline$\Delta l=0$ & 0.08 & 0.10 \\
\hline$\Delta l=-0.17$ & 0.26 & 0.28
\end{tabular}

It must again be emphasized that these changes represent long-run 
changes, disregarding cyclic influences. They seem to be very favorable for the case of shorter hours: an increase of 8 to 10 per cent of employment would result when weekly wages are kept constant and one of 26 to 28 per cent if hourly wages are kept constant.

It will be clear that the effect on total consumption is less favorable. Using the formula for $u$ (case 3) we find:

\begin{tabular}{c|c|c}
$\Delta u$, for: & $\Delta h=0$ & $\Delta h=0.02$ \\
\hline$\Delta l=0$ & $-0.15(-10 \%)$ & $-0.23(-15 \%)$ \\
\hline$\Delta l=-0.17$ & $+0.07(+5 \%)$ & $-0.02(-1 \%)$
\end{tabular}

The percentage changes have been given in brackets $(u=1.51)$.

\section{Concluding Remarks}

We have not yet exhausted our formulae. They enable us, in principle, to calculate consequences of other structural changes and also to calculate the effects on the other variables such as $p, q, E$, etc. Part of this may be left to the reader and to later publications. As an example, one further problem may be considered, viz., to find the increase in total incomes $a l+E$ or $\Delta a+\Delta E$ for a given increase in $M$, obtained by additional investments $\Delta M$ financed by credit creation. Evidently this is the problem of the multiplier, but under conditions somewhat different from those assumed by Kahn and Keynes. A reserve capacity has been assumed to exist in this sense that less and less "good" investment goods are available for increases in production [cf. equations (3) and (8)]. No dole has been supposed to exist and the community considered is a closed one. From Table 2 we find: $\Delta a+\Delta E$ $=(8.72+5.70) \Delta M$, which means a multiplier of about 14 .

Similar calculations ${ }^{4}$ have been made for Holland; they show, in many respects, similar results; but the multiplier is found-as it should be-to be much lower, viz., of the order of magnitude of 2 .

\section{Central Statistical Office}

The Hague; Netherlands

${ }^{4}$ These will be published in a Report made by the Netherlands Central Statistical Office on the request of the High Labor Council. 